\title{
Service Quality of Online Shopping Platforms: A Case-Based Empirical and Analytical Study
}

\author{
Tsan-Ming Choi, ${ }^{1}$ Pui-Sze Chow, ${ }^{1}$ Bowood Kwok, ${ }^{1}$ Shuk-Ching Liu, ${ }^{1}$ and Bin Shen ${ }^{2}$ \\ ${ }^{1}$ Business Division, Institute of Textiles and Clothing, The Hong Kong Polytechnic University, Hung Hom, Kowloon, Hong Kong \\ ${ }^{2}$ School of Glorious Sun of Business and Management, Donghua University, Shanghai 200051, China \\ Correspondence should be addressed to Bin Shen; binshenjerry@gmail.com
}

Received 29 July 2013; Accepted 2 September 2013

Academic Editor: Kannan Govindan

Copyright (C) 2013 Tsan-Ming Choi et al. This is an open access article distributed under the Creative Commons Attribution License, which permits unrestricted use, distribution, and reproduction in any medium, provided the original work is properly cited.

\begin{abstract}
Customer service is crucially important for online shopping platforms (OSPs) such as eBay and Taobao. Based on the wellestablished service quality instruments and the scenario of the specific case on Taobao, this paper focuses on exploring the service quality of an OSP with an aim of revealing customer perceptions of the service quality associated with the provided functions and investigating their impacts on customer loyalty. By an empirical study, this paper finds that the "fulfillment and responsiveness" function is significantly related to the customer loyalty. Further analytical study is conducted to reveal that the optimal service level on the "fulfillment and responsiveness" function for the risk averse OSP uniquely exists. Moreover, the analytical results prove that (i) if the customer loyalty is more positively correlated to the service level, it will lead to a larger optimal service level, and (ii) the optimal service level is independent of the profit target, the source of uncertainty, and the risk preference of the OSP.
\end{abstract}

\section{Introduction}

Observing from the popular and growing trend of electronic commerce (e-commerce), there is no doubt that business such as those selling fashion-related products can now use the Internet to interact with customers and gain the competitive edge. The critical determinants of success in e-commerce cover not only the low price strategy but also its service quality (i.e., e-service quality) $[1,2]$. In the literature, Zeithaml [2] defines e-service quality as an overall customer assessment and judgment of e-service delivery in the virtual marketplace. To measure the customer perceptions of service quality, the SERVQUAL model, which was first developed by Parasuraman et al. [3], has been widely adopted. The SERVQUAL model includes five dimensions, namely, tangibles, reliability, responsiveness, assurance, and empathy. Previous studies on the measurement of e-service quality focus on the "rewording" of the original scale items of the application of the SERVQUAL model. Yet, service researchers ought to pay extra attention to e-services in the field of service quality, because assessing service quality in e-commerce might be different from that in physical marketplace service [4]. As such, it is necessary to reformulate the SERVQUAL scale items in e-commerce context [5].

With the prevailing trend of online shopping in Hong Kong and China, http://taobao.com/ becomes one of the hottest online shopping platforms (OSPs) despite its keen competition with internationally renowned companies such as yahoo auction and eBay as well as domestic companies such as Jingdong and Dangdang. Yahoo auction and eBay enable consumers to search for products globally and hence have their niche. However, it is interesting to observe that http://taobao.com/ has successfully penetrated into the Hong Kong and Macau e-tailing markets by its price leadership, special features, and a wide product range. More importantly, http://taobao.com/ also enjoys the geographic advantage of pooling local sellers together with a low local delivery cost, and convenient and unobstructed communication with seller. The exclusive functions featured in http://taobao.com/ include (i) Searching Functions, (ii) Guarantee of Trade Safety, (iii) Aliwangwang, (iv) Alipay, and (v) Taodot. All these features of http://taobao.com/ are then able to 
TABLE 1: Featured functions of http://taobao.com/.

\begin{tabular}{ll}
\hline Featured functions & Descriptions \\
Search function & $\begin{array}{l}\text { Search by keywords, show items in icons or lists or by default arrangement, sort searching product according } \\
\text { to price, credibility, transaction volume, and store location, and lastly sort the production categories into } \\
\text { brand new, hot items, product from Taobao mall, second handed, or auction }\end{array}$ \\
\hline Guarantee of trade safety & $\begin{array}{l}\text { Each seller of http://taobao.com/ is required to sign the Guarantee of Trade Safety Agreement which ensures } \\
\text { that s/he commits to provide guaranteed transaction service to customers. Customers are able to request for } \\
\text { refund if they receive any incorrect goods. The terms of guarantee include } 7 \text { days of unconditional return, no } \\
\text { counterfeits, } 3 \text { times refund for counterfeits, maintenance within } 30 \text { days of purchase, and express delivery }\end{array}$ \\
\hline Aliwangwang & $\begin{array}{l}\text { It is the pervasive communication between buyer and seller prior to the purchase through its embedded } \\
\text { proprietary instant chat program. Customers can enquire about products, engage in bargaining, display of } \\
\text { product image in the messenger window, and make queries of the delivery status and logistic message }\end{array}$ \\
\hline Alipay & $\begin{array}{l}\text { It is an escrow-based online payment platform. It aims to enable fast money transaction with higher security } \\
\text { and privacy }\end{array}$ \\
\hline Taodot & $\begin{array}{l}\text { It is an online platform that provides the value adding service for Alipay users. This convenient tool enables } \\
\text { Taobao users who do not have an RMB account to pay for their online transactions }\end{array}$ \\
\hline
\end{tabular}

differentiate it from other competing OSPs and obtain its niche. Table 1 summarizes the major featured functions of http://taobao.com/.

For the research goal and contribution: first, by modifying the SERVQUAL model, this paper attempts to derive the instrument dimensions of e-service quality from the functions featured on http://taobao.com/ and to develop a research model to examine how its e-service quality dimensions affect the customer loyalty. To achieve this research objective, empirical data is collected from 195 online consumers (who have purchased fashion products (as a remark, in this paper, in order to be more concrete, we focus on examining the consumers' experience in purchasing fashion products) on http://taobao.com/). Second, based on the empirical finding, this paper further analytically develops and explores the optimal service decision on the function which is critical to the OSP. We believe that the research findings derived from this paper can contribute to the literature on service management, and they also provide important managerial insights on OSP's operations.

\section{Literature Review}

2.1. Review of Related Empirical Studies and Models. SERVQUAL is a multiple-item scale for measuring customer perception of service quality [3]. According to those five dimensions of the SERVQUAL model, we note that the tangibles dimension means the physical facilities and the appearance of personnel; the reliability dimension refers to the company's ability to perform the promised service dependably and accurately; the responsiveness dimension relates to the willingness to help customers and provide prompt service; the assurance dimension means the employee knowledge base which induces customer trust and confidence; and finally, the empathy dimension is about caring and individualized attention provided to customers by the service provider.

Recently, SERVQUAL scale has been employed to measure the corresponding system service quality in ecommerce $[6,7]$. Most existing research on e-service quality measurement focuses on rewording the SERVQUAL scale items (e.g., [8-10]). The challenges in measuring web-based service quality mainly come from the differences between web-based and traditional customer service. Parasuraman and Grewal [4] suggest that revisions of the classical SERVQUAL dimensions are necessary because for web-based service quality, customers interact with technology rather than the traditional service personnel. Moreover, several studies have proposed that the SERVQUAL scale items should be reformulated in the online shopping context $[5,11]$.

As a remark, there are criticisms over the applicability of the SERVQUAL model. Among them, one important critique is on the fact that SERVQUAL's five dimensions are not universally applicable, and that the model fails to draw on established economic, statistical, and psychological theories [12]. In fact, the most significant criticism is the stability of dimensions and items across different industries [13]. Other criticisms include (i) its focus on the process of service delivery rather than the outcomes of the service encounter, and (ii) the probable respondent error from the reversed polarity of items in the scale in the consumer survey $[12,14]$. Parasuraman et al. [15] also comment that the SERVQUAL is far from perfect as it is not general enough, but they argue that it does provide the basic skeleton for others to study service quality even though some degree of customization is probably needed (e.g., adding context-specific items). Although SERVQUAL's construct validity is being challenged, it is still the most widely used model employed to measure customer expectations and perceptions of service quality.

E-service quality is defined as how customers judge and evaluate the e-service being delivered to them [11]. On the evaluation of websites service quality, Parasuraman et al. [16] introduce the E-S-QUAL and E-RecS-QUAL scales which extend the SERVQUAL model in evaluating the service quality in the "online shopping context." E-S-QUAL is a multipleitem scale consisting of efficiency ( 8 items), system availability (4 items), fulfillment (7 items), and privacy (3 items) dimensions. E-S-QUAL provides the first formal definition of Web site service quality and it is a framework for consumer evaluation of electronic services. Notice that Zeithaml [2] 


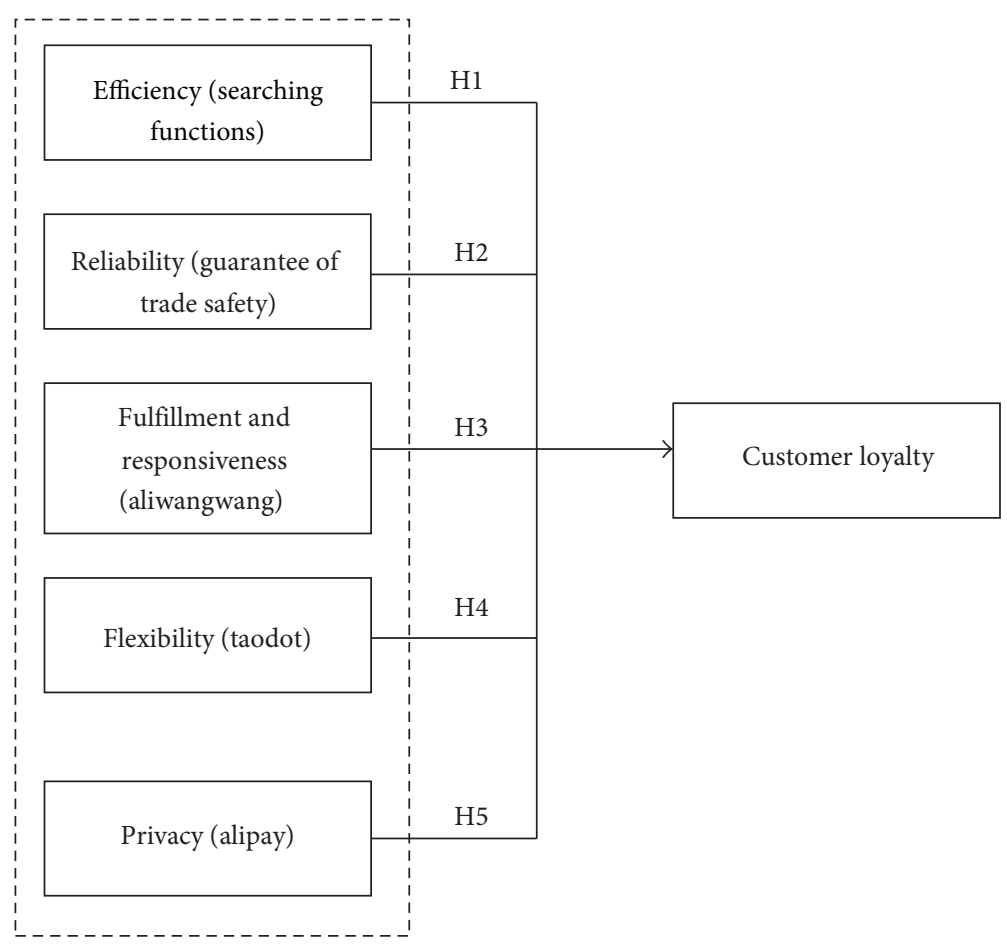

FIGURE 1: The proposed ESQ-OSP e-service quality model (Customized for http://taobao.com/'s case).

suggests that e-service quality is a multidimensional construct, and the electronic service recovery construct involves dimensions different from the core e-service quality. From eservice perspective, Parasuraman et al. [16] develop E-RecSQUAL specifically to measure e-service quality, and this scale brings out a new perspective by utilizing valuable consumer information on service recovery issues. Actually, E-RevSQUAL is a subscale that contains items focusing on handling service problems and inquiries, and being effective to those who used to have nonroutine behaviors on the online store. The basic E-S-QUAL Scale (relevant for a Web site's entire customer base) is a four-dimensional, 22-item scale, whereas E-RecS-QUAL (relevant for the portion of the customer base with recovery service experience) is a three-dimensional scale with 7 items. E-RevS-QUAL is used to stimulate and facilitate additional scholarly research on e-service quality and also assist practitioners in systematically assessing and improving e-service quality together with E-S-QUAL [16].

Notice that Parasuraman et al. [16] cannot evaluate the validity and psychometric properties of the scale in their study due to the insufficient sample size [17]. The main reason of the limited sample size is that the number of consumers who encounter service problems is relatively smaller than those who do not. Hence, their study is neither fully generic nor absolutely reliable. Moreover, E-S-QUAL is still a recent model (2005) which requires more time to verify. As a remark, observe that there are different versions of the modified E-S-QUAL for identifying the best e-service quality dimensions with the goal of examining different online businesses [17]. Given the limitation of the existing models, this paper proposes and explores an empirical model which incorporates the service quality dimensions extracted from SERVQUAL, E-S-QUAL, and E-RevS-QUAL which we believe can appropriately represent and study the service quality in an OSP such as http://taobao.com/. (For some more recent literature on service quality related to online shopping, see Rossitier [18], Ding et al. [19], Ha and Stoel [20], and Hu and Qiang [21].)

Regarding the research motivation, notice that prior studies in the literature have suggested that perceived service quality positively influences customer satisfaction and purchase intentions $[22,23]$. However, to the best of our knowledge, in the context of online shopping, the impacts of how service quality dimensions affect overall e-service quality and the customer loyalty are still under-explored. This paper, hence, contributes to the literature by partially filling this research gap. Moreover, by building the empirical data-based analytical model, we explore the optimal service decision for the OSP and derive various important insights.

2.2. Empirical Hypotheses Development. After combining and synthesizing the existing construct of both service quality and e-service quality, based on the reviewed literature, we propose a perceived e-service quality construct for an OSP (ESQOSP) with http://taobao.com/ taken as the specific case. The proposed e-service quality model comprises 5 dimensions extracted from SERVQUAL, E-S-QUAL, and E-RevS-QUAL models, namely, efficiency, reliability, fulfillment and responsiveness, flexibility, and privacy as shown in Figure 1.

We now describe each dimension under the proposed ESQ-OSP model. First, in Parasuraman et al. [16], efficiency is reflected by whether the web site is simple to use, structured 
properly, and requires a minimum amount of information to be inputted by the customer. As a result, the online shipping platform is efficient if (i) it is easy for customers to find what they need, (ii) it enables customers to complete a transaction quickly, and (iii) the information provided by the web site is well organized. Thus, service quality of the searching functions of http://taobao.com/ can reflect its efficiency. Therefore, we have the following hypothesis.

\section{H1: efficiency positively influences the customer loyalty of http://taobao.com/.}

Reliability here refers to the consistency of performance and dependability of companies [3]. Reliability can make customers recognize the consistency and credibility of the company. In e-commerce, it is vital to make customers trust the promises that the OSP made. Obviously, "The Guarantee of Trade Safety" function of http://taobao.com/ is related to ensuring reliability, and it is hypothesized to influence customer loyalty:

\section{H2: reliability positively influences the customer loyalty of http://taobao.com/.}

Fulfillment refers to the extent in which the website's promises on order delivery and items availability are fulfilled. To be specific, fulfillment is reflected by whether the OSP can ensure items being available to delivery within an acceptable time frame and guarantee quick delivery as promised [16]. For http://taobao.com/, the functions of Aliwangwang are able to represent fulfillment. Responsiveness means the effective handling of problems and returns through the site. It provides customers with convenient options for returning items. The website promises to handle product returns and offers a meaningful guarantee so that customers would feel more comfortable [16]. As one of the service quality dimensions, contacting the seller through Aliwangwang reflects the responsiveness of http://taobao.com/. Therefore, it is hypothesized that:

\section{H3: "fulfillment and responsiveness" positively influ- ence the customer loyalty of http://taobao.com/.}

Flexibility refers to the choice of payment methods. For example, when purchasing products in http://taobao.com/, Taodot is an innovative way for the users to pay online safely. Consumers can buy Taodot to deposit/add values in their Alipay account. It is safer and shows its flexibility if consumers are in Hong Kong or Macau. Then, the following hypothesis is proposed.

\section{H4: flexibility positively influences the customer loyalty of http://taobao.com/.}

Privacy refers to the degree to which the website is safe and customer information is well-protected. This dimension holds an important position in e-commerce and is critical in e-service. Customers perceive significant risks in the virtual environment of e-commerce stemming from the possibility of improper use of their personal financial data. The privacy function in http://taobao.com/ is mainly associated with Alipay. Accordingly, it is hypothesized that:

\section{H5: privacy positively influences the customer loyalty of http://taobao.com/.}

2.3. Review of Related Analytical Models. In the literature on analytical research, there are many recent studies related to the optimal service decision. For example, Xiao et al. [24] explore the optimal service strategy with optimal pricing decisions in a retail supply chain with risk averse players. They consider the situation in which the retailer has to choose whether to provide a service guarantee (SG) or to provide no service guarantee (NSG). They relate the optimal choice to the supplier's degree of risk aversion and the consumer's sensitivity to service reliability. They find that endogenization of wholesale pricing decision will raise the retailer's motivation to adopt SG strategy if the consumer is sufficiently risk averse. Choi [25] examines the optimal service charge for consumer product returns under mass customization operations. He explores two cases which cover the scenario when the mass customization company is risk-neutral and risk-averse. He derives the closed-form expression of the optimal return service charge for each case. He analytically shows how the mass customization company's degree of risk aversion affects the optimal return service charge policy. In addition, he derives the analytical conditions under which it is optimal for the mass customization company to offer a free return with a full refund policy. $\mathrm{Hu}$ and Qiang [21] investigate an online supply chain analytical model which is consisted of manufacturers, express service providers, and electronic retailers. They consider the situation in which consumers who purchase products from the electronic retailers can choose to adopt the express delivery service or simply pick up the products themselves. At the same time, the express service companies can invest on service quality improvement. They develop the variational inequality formulation and generate insights via exploring the equilibrium. As reviewed above, it is evidenced that analytical modeling research is commonly adopted to explore optimal service decisions and strategies in the literature. However, to the best of our knowledge, none of them explore the problem associated with the empirical service quality framework. Thus, we believe that this paper is the first one which investigates the service quality problem for OSPs by combining both empirical and analytical approaches.

\section{Data Collection and Empirical Data Analysis}

A consumer questionnaire survey is conducted. 250 questionnaires are distributed via social network websites under a convenience sampling approach. Receivers are invited to complete the questionnaire if they know http://taobao.com/ and have visited it. 190 valid questionnaires are received and employed for statistical analysis finally.

The questionnaire is divided into 8 parts. The first part is used to collect the demographic data of the respondents. The second part is employed to examine the purchase behavior of the respondents on http://taobao.com/. The rest of the questionnaire is divided into 6 subparts to investigate the perceptions of http://taobao.com/ users on the 5 functions provided by http://taobao.com/ and their loyalty towards the 
OSP. The 7-point Likert scale is used, in which 1 represents "strongly disagree" and 7 represents "strongly agree".

3.1. Descriptive Statistics. Among all the completed questionnaires received, $64 \%$ of the respondents have purchased fashion products on http://taobao.com/ before while 36\% have not. Thus, the remaining analysis will be based on the responses of these $64 \%$ of the collected sample in order to get valid data. To be specific, these consumers are considered as http://taobao.com/'s customers (for fashion products). The percentage of the http://taobao.com/ customers who browse products on http://taobao.com/ daily occupies $8 \%$. $13 \%, 11 \%$, and $26 \%$ of http://taobao.com/'s customers browse products on http://taobao.com/ 2-3 times a week, once a week, and 2-3 times per month, respectively. The percentages of the http://taobao.com/'s customers who buy products via http://taobao.com/ daily, 2-3 times a week, once a week, and $2-3$ times a month are $3 \%, 2 \%, 2 \%$, and $11 \%$, respectively.

Regarding spending, 75\% of the http://taobao.com/ users spend less than $\$ 500$ on http://taobao.com/ monthly. $19 \%$ of them spend $\$ 500-1000$ on Tobao.com monthly. $2 \%, 1 \%$, and $3 \%$ of the users spend $\$ 1000-1500, \$ 1500-$ 2000, and more than $\$ 2000$ on http://taobao.com/ monthly, respectively. Regarding the users shopping experiences on http://taobao.com/, ranking their enjoyment (in a 1-7 scale with 7 being the best), more than half of the respondents score their enjoyment level strictly above 4 (64\%). 36\% of them score as score 5 which represents the greatest group, $23 \%$ of them score as score 6 , and $5 \%$ of them rank it 7 . The percentage of score 4 , which means neutral excitement, occupies $15 \%$. The percentages of low scores 1,2 , and 3 occupy $5 \%, 5 \%$, and $11 \%$, respectively.

3.2. Hypotheses Testing. Before testing hypotheses, we first conduct the reliability test to assess the internal consistency of the variables. Reliability test is measured by the Cronbach's alpha in which the alpha value of 0.7 or above is widely recognized as an acceptable level of reliability [27]. The Cronbach alpha values for Searching functions, Guarantee of Trade Safety, Aliwangwang, Alipay, and Taodot are found to be $0.933,0.919,0.956,0.958$, and 0.921 , respectively. All of them are higher than the acceptable level. Besides, the seven questions of customer loyalty are tested in this part. The Cronbach alpha value of the customer loyalty is 0.905 which also exceeds the acceptable level. Thus, we conclude that all these dimensions are sufficiently reliable. Next, we proceed to test the relationships of the five featured functions and customer loyalty by performing multiple linear regression analysis. It is shown that there is a statistically significant relationship between customer loyalty and the Aliwangwang function. The related statistical results of hypotheses are summarized in Table 2. As such, hypothesis H3 is supported (more details on the statistical analysis can be found in thesis research of Kwok [26]).

\section{Empirical Findings and Insights}

From the above empirical analysis, first of all, we know that the factor of "fulfillment and responsiveness (Aliwangwang function)" is the most critical one as it most strongly affects customer loyalty of http://taobao.com/s customers (who purchased fashion products before). Observe that this result is consistent with the findings in the traditional service context which suggests that customers expect quick feedback on their requests and suggestions for improvements [2]. For http://taobao.com/'s case, it can be explained by the function of Aliwangwang which provides instant messaging for http://taobao.com/'s users to send messages to the sellers. This enhances the fulfillment of http://taobao.com/ users on queries and needs related to product delivery and item availability. This function also can reduce the customers' doubt on the product that they want to buy and further confirm their purchase decision. In addition, the customers can contact the sellers whenever the sellers are online with a simple click. This function extends the accessibility of the sellers/online stores without the control of the store operating hours. With Aliwangwang, http://taobao.com/ users are able to obtain adequate product information even if it is not given on the product web page. It increases the convenience of http://taobao.com/. Since it is a unique feature provided by http://taobao.com/ but not its close competitors, it becomes a major niche for http://taobao.com/.

Second, observe that only one hypothesis among the proposed five is proven to be true statistically. A possible reason may be given as follows. Unlike the traditional physical store or other kinds of online electronic retailers such as http://www.amazon.com/, etc., http://taobao.com/ is an online marketplace in which there are thousands of independent retailers. As a result, customers' perception on the service quality and their loyalty towards the OSP may be affected by their buying experience with the individual retailers. Owing to the fundamental differences, many hypotheses which apply for the more traditional bricksand-mortar retailing/electronic retailing do not hold for the OSPs such as http://taobao.com/. In addition, notice that in http://taobao.com/, communication with individual sellers is especially important. In fact, customers would like to gather more information so that they can make better choice from a large variety of independent retailers selling similar products on the platform. This accounts for the support of Hypothesis 3 (which is about Aliwangwang and related to communication aspect).

Third, we know that a higher level of "fulfillment and responsiveness (Aliwangwang function)" will lead to a higher level of customer loyalty. According to Edvardsson et al. [28], customer loyalty will positively affect the revenue of the OSP, it will be thus interesting to analytically examine whether there exists an optimal level of "fulfillment and responsiveness" for the OSP. We, hence, further conduct an analytical study in the next section.

\section{Analytical Service Optimization Model and Findings}

Based on the empirical findings from Section 4, we proceed to build an analytical model for further analysis. First, from the linear regression analysis conducted in Section 4 (see Table 2), we notice that the level of customer loyalty $l$ is related 
TABLE 2: Summary of regression analysis.

\begin{tabular}{lccc}
\hline Corresponding hypothesis & Independent variable & Standardized coefficient & $t$-value \\
\hline Hypothesis 1 & Efficiency & -0.057 & -0.575 \\
Hypothesis 2 & Reliability & 0.087 & 0.573 \\
Hypothesis 3 & Fulfillment \& responsiveness & 0.582 & 0.896 \\
Hypothesis 4 & Flexibility & 0.062 & 2.255 \\
Hypothesis 5 & Privacy & 0.307 & 0.406 \\
\hline
\end{tabular}

Remarks:

dependent variable: customer loyalty.

${ }^{* *}$ hypothesis is supported.

to the level of "fulfillment and responsiveness" $\lambda$ in a linear function as follows,

$$
l=a+b \lambda
$$

where $a, b>0$.

Second, since it is intuitive that a higher level of customer loyalty $l$ will "stochastically" (it means expectedly, the revenue should be higher but the exact magnitude is unknown) lead to a higher revenue $R(l)$ for the OSP such as http://taobao.com/, we have the following:

$$
R(l)=G(l)+\varepsilon,
$$

where (i) $G(l)$ is an increasing function of $l$. For analytical tractability, we further assume $G(l)$ as a concave function. (ii) $\varepsilon$ is a random variable which captures the noise (i.e., uncertainty) associated with $R(l)$. Following the literature [29], we model it to follow a symmetric distribution such as the normal distribution with a zero mean and constant variance $\sigma^{2}$.

Third, providing a higher level of "fulfillment and responsiveness" $\lambda$ requires resource. We, hence, define the respective cost as $C(\lambda)$ which is an increasing function of $\lambda$. Similar to $G(l)$, we assume $C(\lambda)$ as a convex function for analytical tractability. Notice that the above functional definitions are all intuitive and rather general.

With the above model, we can derive the profit $\pi(\lambda)$, the expected profit $E[\pi(\lambda)]$, and the variance of profit $V[\pi(\lambda)]$ as functions of $\lambda$ as follows:

$$
\begin{gathered}
\pi(\lambda)=R(l)-C(\lambda) \\
=G(a+b \lambda)-C(\lambda)+\varepsilon, \\
E[\pi(\lambda)]=G(a+b \lambda)-C(\lambda), \\
V[\pi(\lambda)]=\sigma^{2} .
\end{gathered}
$$

Because e-business is known to be a risky operation, we argue that the OSP has concern on risk and possesses a risk averse attitude [24]. As such, we employ the following meanvariance safety first measure $(\operatorname{SFM}(\lambda))$ as the objective function (for the modeling of risk averse optimization objectives, see Xiao and Choi [30], Chiu and Choi [31], Chiu et al. [32], Choi and Chiu [33], Choi et al. [34], Choi [35], and Shen et al. [36]) for the OSP as follows:

$$
\operatorname{SFM}(\lambda)=\frac{(E[\pi(\lambda)]-\beta)}{\sqrt{V[\pi(\lambda)]}},
$$

where $\beta$ is the expected profit target that the OSP wants to achieve.

For the meaning behind $\operatorname{SFM}(\lambda)$, please notice that by Bienayme-Tchebycheff inequality, we have the following inequality:

$$
\begin{gathered}
P(|\pi(\lambda)-E[\pi(\lambda)]| \geq E[\pi(\lambda)]-\beta) \leq \frac{V[\pi(\lambda)]}{(E[\pi(\lambda)]-\beta)^{2}} \\
\quad \Longrightarrow P(\pi(\lambda) \leq \beta) \leq \frac{V[\pi(\lambda)]}{(E[\pi(\lambda)]-\beta)^{2}} \equiv \frac{1}{\operatorname{SFM}(\lambda)^{2}}
\end{gathered}
$$

Thus, the RHS of (6) gives the analytical upper bound for $P(\pi(\lambda) \leq \beta)$. Obviously, maximizing $\operatorname{SFM}(\lambda)$ yields a minimized upper bound for $P(\pi(\lambda) \leq \beta)$ and hence $\operatorname{SFM}(\lambda)$ is called the safety first measure (see [37]).

With the above model, we define (7), and then have Proposition 1 . Notice that $S_{G}(\lambda)$ and $S_{C}(\lambda)$ are the first order derivatives of $G(a+b \lambda)$ and $C(\lambda)$, respectively, and they also represent the corresponding slopes as follows:

$$
\begin{gathered}
\lambda_{\mathrm{SFM}}^{*}=\arg \operatorname{maxSFM}_{\lambda}(\lambda), \\
\lambda_{\mathrm{EP}}^{*}=\arg \max _{\lambda} E[\pi(\lambda)], \\
S_{G}(\lambda)=\frac{d G(a+b \lambda)}{d \lambda}, \\
S_{C}(\lambda)=\frac{d C(\lambda)}{d \lambda} .
\end{gathered}
$$

Proposition 1. $\lambda_{S F M}^{*}$ uniquely exists and it is equal to $\arg _{\lambda}\left\{S_{G}(\lambda) / S_{C}(\lambda)=1\right\}$.

Proof of Proposition 1. All proofs are placed in the Appendix.

Proposition 1 first presents the uniqueness feature of the optimal level of fulfillment and responsiveness (i.e. optimal service level) which maximizes the safety first objective. It then reveals that this optimal service level is the one which equalizes $S_{G}(\lambda)$ and $S_{C}(\lambda)$. In other words, when the rates of change of $G(a+b \lambda)$ and $C(\lambda)$ are the same, the corresponding service level $\lambda$ is optimal. From Proposition 1 , we have Proposition 2. 
Proposition 2. (a) A larger $b$ implies a larger $\lambda_{S F M}^{*}$ (b) $\lambda_{S F M}^{*}$ is independent of $\beta$ and $\sigma$.

Observe that a larger $b$ means that the customer loyalty is more positively correlated to the service level $\lambda$. Proposition 2(a) hence indicates that it will lead to a bigger optimal service level because the optimal solution refers to the one which balances the increase of revenue $S_{G}(\lambda)$ and rise of cost $S_{C}(\lambda)$. It is also interesting to note from Proposition 2(b) that $\lambda_{\mathrm{SFM}}^{*}$ is independent of $\beta$ and $\sigma$. This finding can be explained by the fact that the variance of profit $V[\pi(\lambda)]$ is a constant which is independent of the service level $\lambda$. Thus, the corresponding optimal service level is not related to $\sigma$ as well as the expected profit target $\beta$, and will in fact behave like the risk neutral case as shown in Proposition 3 below.

Proposition 3. $\lambda_{E P}^{*}$ uniquely exists and $\lambda_{S F M}^{*}=\lambda_{E P}^{*}$.

Proposition 3 shows a rather surprising result that the risk averse and risk neutral OSPs will have the same optimal service levels for this particular case. In other words, irrespective of the risk preference, the optimal service level is the same. This finding is important because it shows the fundamental difference between different kinds of operations management problems. For example, for inventory planning under uncertainty, the optimal inventory decision for the risk averse and risk neutral cases will be different. However, in service optimization, the situation can be different as shown here.

\section{Concluding Remarks}

We conclude by discussing some research implications derived from the discussions above. First, the empirical findings suggest that in order to enhance customer loyalty, online stores should develop marketing strategies to enhance "fulfillment and responsiveness" since they strongly affect customer loyalty. http://taobao.com/ has devoted valuable corporate resources to it and we argue that http://taobao.com/ can further improve the functions of Aliwangwang to achieve even better communication between the sellers and http://taobao.com/ users. Some probable enhancements including inserting flash games and converting to smartphone apps can all help to attract the http://taobao.com/ users to use Aliwangwang. Furthermore, http://taobao.com/ can make use of Aliwangwang to obtain personalized data related to the customers' preferences. As a result, a higher degree of web site customization (e.g., based on past purchases and other customers' information collected) can be provided to individual customers.

Second, for the empirical result driven analytical studies, we find that the optimal service level on "fulfillment and responsiveness" function for the risk averse OSP uniquely exists and can be expressed as the service level which balances the increase of revenue $S_{G}(\lambda)$ and the rise of cost $S_{C}(\lambda)$. We further show that if the customer's loyalty is more positively correlated to the service level $\lambda$, it will lead to a larger optimal service level. Moreover, the optimal service level under the safety first objective is independent of profit target $\beta$ and uncertainty threshold $\sigma$. Finally, we analytically prove that the optimal service level does not depend on the risk preference of the OSP.

For future research, there are two directions. Empirically, it is useful to examine more functions of OSP such as http://taobao.com/. This paper only focuses on the several core functions specifically adopted by http://taobao.com/ and there are some more which deserve further explorations. Besides, unlike the traditional bricks-and-mortar and electronic retailers, the operation of http://taobao.com/ involves thousands of independent sellers. As a result, the customers' perceived service quality of the platform would be considerably affected by their buying experience with individual sellers. In the future, it is worth investigating the modification of the existing service quality-scale measurement to cater for this specific type of new business model. The second direction for further studies relates to the theoretical analysis based on more comprehensive economics analytical models. We believe that the findings revealed by this paper can lay the foundation for many further empirical and analytical studies.

\section{Appendix}

\section{All Proofs of Propositions}

Proof of Proposition 1. From (4), we have

$$
\operatorname{SFM}(\lambda)=\frac{(E[\pi(\lambda)]-\beta)}{\sqrt{V[\pi(\lambda)]}} .
$$

Since $V[\pi(\lambda)]=\sigma^{2},($ A.2) becomes

$$
\begin{gathered}
\operatorname{SFM}(\lambda)=\frac{(E[\pi(\lambda)]-\beta)}{\sigma} . \\
\frac{d \operatorname{SFM}(\lambda)}{d \lambda}=\frac{d E[\pi(\lambda)] / d \lambda}{\sigma} \\
=\frac{d[G(a+b \lambda)-C(\lambda)] / d \lambda}{\sigma} . \\
\frac{d^{2} \operatorname{SFM}(\lambda)}{d \lambda^{2}}=\frac{1}{\sigma}\left(\frac{d^{2} G(a+b \lambda)}{d \lambda^{2}}-\frac{d^{2} C(\lambda)}{d \lambda^{2}}\right) .
\end{gathered}
$$

Since $G(a+b \lambda)$ is concave and $C(\lambda)$ is convex, $d^{2} \operatorname{SFM}(\lambda) / d \lambda^{2}<0$ which means $\operatorname{SFM}(\lambda)$ is concave, and $\lambda_{\mathrm{SFM}}^{*}$ uniquely exists. In addition, notice that $\lambda_{\mathrm{SFM}}^{*}=$ $\arg _{\lambda}[d \operatorname{SFM}(\lambda) / d \lambda=0]$. Thus, we have $\lambda_{\text {SFM }}^{*}=\arg _{\lambda}\left\{S_{G}(\lambda) /\right.$ $\left.S_{C}(\lambda)=1\right\}$.

Proof of Proposition 2. Part (a): notice that $\lambda_{\mathrm{SFM}}^{*}=$ $\arg _{\lambda}\left\{S_{G}(\lambda) / S_{C}(\lambda)=1\right\}$ and

$$
\begin{aligned}
S_{G}(\lambda) & =\frac{d[G(a+b \lambda)]}{d \lambda} \\
& =\frac{d(a+b \lambda)}{d \lambda} \frac{d G(a+b \lambda)}{d(a+b \lambda)}=b \frac{d G(a+b \lambda)}{d(a+b \lambda)} .
\end{aligned}
$$

Thus, $\lambda_{\mathrm{SFM}}^{*}=\arg _{\lambda}\left\{S_{G}(\lambda) / S_{C}(\lambda)=1\right\}=\arg \left\{S_{C}(\lambda)=b(d G(a+\right.$ $b \lambda) / d(a+b \lambda))\}$. 
Define $f(\lambda)=S_{C}(\lambda) /\left.(d G(l) / d l)\right|_{l=a+b \lambda}$. Consider

$$
\begin{aligned}
f^{\prime}(\lambda)= & \frac{1}{\left(\left.(d G(l) / d l)\right|_{l=a+b \lambda}\right)^{2}} \\
& \times\left(\left(\left.\frac{d G(l)}{d l}\right|_{l=a+b \lambda}\right) \frac{d S_{C}(\lambda)}{d \lambda}\right. \\
& \left.\quad-S_{C}(\lambda) \frac{d}{d \lambda}\left(\left.\frac{d G(l)}{d l}\right|_{l=a+b \lambda}\right)\right) .
\end{aligned}
$$

We have

(a) $d S_{C}(\lambda) / d \lambda=d^{2} C(\lambda) / d \lambda^{2}>0[\because C(\lambda)$ is convex in $\lambda]$,

(b) $\left.(d G(l) / d l)\right|_{l=a+b \lambda}>0[\because G(l)$ is increasing in $l]$,

(c) $S_{C}(\lambda)=d C(\lambda) / d \lambda>0[\because C(\lambda)$ is increasing in $\lambda]$,

(d) $(d / d \lambda)\left(\left.(d G(l) / d l)\right|_{l=a+b \lambda}\right)=\left[d^{2} G(l) / d l^{2} \cdot d(l=a+\right.$ $b \lambda) / d \lambda]_{l=a+b \lambda}=b\left(d^{2} G(l) / d l^{2}\right)_{l=a+b \lambda}<0[\because G(l)$ is concave in $l$.

Therefore, we have $f^{\prime}(\lambda)>0$ for all $\lambda$. In other words, $f(\lambda)$ is increasing in $\lambda$. Therefore, a larger $b$ implies a larger $\lambda_{\mathrm{SFM}}^{*}$.

Part (b): since both $S_{G}(\lambda)$ and $S_{C}(\lambda)$ are independent of $\beta$ and $\sigma$, it is obvious that $\lambda_{\mathrm{SFM}}^{*}=\arg _{\lambda}\left\{S_{G}(\lambda) / S_{C}(\lambda)=1\right\}$ is also independent of $\beta$ and $\sigma$.

Proof of Proposition 3. First notice that $E[\pi(\lambda)]$ is a concave function. Thus, $\lambda_{\mathrm{EP}}^{*}$ uniquely exists. Second, from (A.3), we have

$$
\frac{d \operatorname{SFM}(\lambda)}{d \lambda}=\frac{d E[\pi(\lambda)] / d \lambda}{\sigma}=\frac{1}{\sigma} \cdot \frac{d E[\pi(\lambda)]}{d \lambda} .
$$

Obviously, from (A.7), we have $\lambda_{\mathrm{SFM}}^{*}=\arg _{\lambda}[d \operatorname{SFM}(\lambda) / d \lambda=$ $0]=\arg _{\lambda}[d E[\pi(\lambda)] / d \lambda=0]$, which is the same as $\lambda_{\mathrm{EP}}^{*}$. Thus, $\lambda_{\mathrm{SFM}}^{*}=\lambda_{\mathrm{EP}}^{*}$.

\section{Authors' Contribution}

All authors have good contribution to the paper and the listing follows their surnames.

\section{Acknowledgments}

The authors thank the editor and the two reviewers for their kind comments on this paper. They declare that none of them is related to the target case company "http://taobao.com/" and other companies named in the paper which may constitute a conflict of interest. This paper is partially supported by the RGC(HK)-GRF under grant a/c of PolyU 5420/10H.

\section{References}

[1] Z. Yang, "Customer perceptions of service quality in internetbased electronic commerce," in Proceedings of the 30th European Marketing Academy Conference (EMAC '01), pp. 8-11, Bergen, Norway, 2001.

[2] V. A. Zeithaml, "Service excellent in electronic channels," Managing Service Quality, vol. 12, no. 3, pp. 135-139, 2002.
[3] Parasuraman, A. L. Berry, and V. A. Zeithaml, "SERVQUAL: a multiple-item scale for measuring consumer perceptions of service quality," Journal of Retailing, vol. 64, no. 1, pp. 12-40, 1988.

[4] A. Parasuraman and D. Grewal, "The impact of technology on the quality-value-loyalty chain: a research agenda," Journal of the Academy of Marketing Science, vol. 28, no. 1, pp. 168-174, 2000.

[5] A. C. R. Van Riel, V. Liljander, and P. Jurriëns, "Exploring consumer evaluations of e-services: a portal site," International Journal of Service Industry Management, vol. 12, no. 4, pp. 359$377,2001$.

[6] S. Devaraj, M. Fan, and R. Kohli, "Antecedents of B2C channel satisfaction and preference: validating e-commerce metrics," Information Systems Research, vol. 13, no. 3, pp. 316-333, 2002.

[7] J. Kim and J. Lee, "Critical design factors for successful ecommerce systems," Behaviour and Information Technology, vol. 21, no. 3, pp. 185-199, 2002.

[8] S. Negash, T. Ryan, and M. Igbaria, "Quality and effectiveness in Web-based customer support systems," Information and Management, vol. 40, no. 8, pp. 757-768, 2003.

[9] Y.-F. Kuo, "A study on service quality of virtual community websites," Total Quality Management and Business Excellence, vol. 14, no. 4, pp. 461-473, 2003.

[10] F. X. Zhu, W. Wymer, and I. Chen, "IT-based services and service quality in consumer banking," International Journal of Service Industry Management, vol. 13, no. 1, pp. 69-90, 2002.

[11] J. Santos, "E-service quality: a model of virtual service quality dimensions," Managing Service Quality, vol. 13, no. 3, pp. 233246, 2003.

[12] F. Buttle, "SERVQUAL: review, critique, research agenda," European Journal of Marketing, vol. 30, no. 1, pp. 8-32, 1996.

[13] H. Stewart, C. Hope, and A. Muhlemann, "Professional service quality: a step beyond other services?" Journal of Retailing and Consumer Services, vol. 5, no. 4, pp. 209-222, 1998.

[14] J. J. Cronin and S. A. Taylor, "Measuring service quality: a reexamination and extension," Journal of Marketing, vol. 56, no. 3, pp. 55-68, 1992.

[15] A. Parasuraman, L. L. Berry, and V. A. Zeithaml, "More on improving service quality measurement," Journal of Retailing, vol. 69, no. 1, pp. 140-147, 1993.

[16] A. Parasuraman, V. A. Zeithaml, and A. Malhotra, "E-S-QUAL a multiple-item scale for assessing electronic service quality," Journal of Service Research, vol. 7, no. 3, pp. 213-233, 2005.

[17] S. Akinci, E. Atilgan-Inan, and S. Aksoy, "Re-assessment of ES-Qual and E-RecS-Qual in a pure service setting," Journal of Business Research, vol. 63, no. 3, pp. 232-240, 2010.

[18] J. R. Rossitier, "ER-SERVCOMPSQUAL: a measure of e-retailing service components quality," Service Science, vol. 1, no. 4, pp. 212-2224, 2009.

[19] D. X. Ding, P. J.-H. Hu, and O. R. L. Sheng, "E-SELFQUAL: a scale for measuring online self-service quality," Journal of Business Research, vol. 64, no. 5, pp. 508-515, 2011.

[20] S. Ha and L. Stoel, "Online apparel retailing: roles of e-shopping quality and experiential e-shopping motives," Journal of Service Management, vol. 23, no. 2, pp. 197-215, 2012.

[21] Y. Hu and Q. Qiang, "An equilibrium model of online shopping supply chain networks with service capacity investment," Service Science, 2013.

[22] R. T. Rust and A. J. Zahorik, "Customer satisfaction, customer retention, and market share," Journal of Retailing, vol. 69, no. 2, pp. 193-215, 1993. 
[23] L. Grønholdt, A. Martensen, and K. Kristensen, "The relationship between customer satisfaction and loyalty: cross-industry differences," Total Quality Management, vol. 11, no. 4-6, pp. S509-S514, 2000.

[24] T. Xiao, T. M. Choi, D. Yang, and T. C. E. Cheng, "Service commitment strategy and pricing decisions in retail supply chains with risk-averse players," Service Science, vol. 4, no. 3, pp. 236252,2012

[25] T. M. Choi, "Optimal return service charging policy for a fashion mass customization program," Service Science, vol. 5, no. 1, pp. 56-68, 2013.

[26] B. Kwok, The service quality of the features of Taobao.com and their impacts on customer loyalty [BA FYP thesis], The Hong Kong Polytechnic University, 2011.

[27] J. P. Robinson, P. R. Shaver, and L. S. Wrightsman, Measures of Personality and Social Psychological Attitudes, Academic Press, San Diego, Calif, USA, 1991.

[28] B. Edvardsson, M. D. Johnson, A. Gustafsson, and T. Strandvik, "The effects of satisfaction and loyalty on profits and growth: products versus services," Total Quality Management, vol. 11, no. 7, pp. S917-S927, 2000.

[29] C.-H. Chiu, T.-M. Choi, and D. Li, "Price wall or war: the pricing strategies for retailers," IEEE Transactions on Systems, Man, and Cybernetics A, vol. 39, no. 2, pp. 331-343, 2009.

[30] T. Xiao and T.-M. Choi, "Purchasing choices and channel structure strategies for a two-echelon system with risk-averse players," International Journal of Production Economics, vol. 120, no. 1, pp. 54-65, 2009.

[31] C.-H. Chiu and T.-M. Choi, "Optimal pricing and stocking decisions for newsvendor problem with value-at-risk consideration," IEEE Transactions on Systems, Man, and Cybernetics A, vol. 40, no. 5, pp. 1116-1119, 2010.

[32] C.-H. Chiu, T.-M. Choi, and X. Li, "Supply chain coordination with risk sensitive retailer under target sales rebate," Automatica, vol. 47, no. 8, pp. 1617-1625, 2011.

[33] T.-M. Choi and C.-H. Chiu, "Mean-downside-risk and meanvariance newsvendor models: implications for sustainable fashion retailing," International Journal of Production Economics, vol. 135, no. 2, pp. 552-560, 2012.

[34] T. M. Choi, P. S. Chow, and T. Xiao, "Electronic price-testing scheme for fashion retailing with information updating," International Journal of Production Economics, vol. 140, pp. 396-406, 2012.

[35] T. M. Choi, "Multi-period risk minimization purchasing models for fashion products with interest rate, budget, and profit target considerations," Annals of Operations Research, 2013.

[36] B. Shen, T. M. Choi, Y. Wang, and C. K. Y. Lo, "The coordination of fashion supply chains with a risk averse supplier by the markdown money policy," IEEE Transactions on Systems, Man, and Cybernetics-Systems, vol. 43, pp. 266-276, 2013.

[37] A. D. Roy, "Safety first and the holding of assets," Econometrica, vol. 20 , no. 3, pp. 431-449, 1952. 


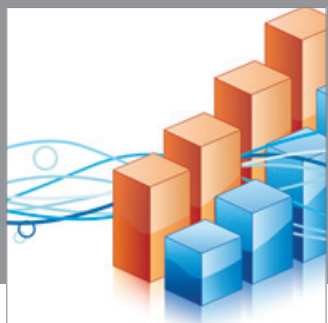

Advances in

Operations Research

mansans

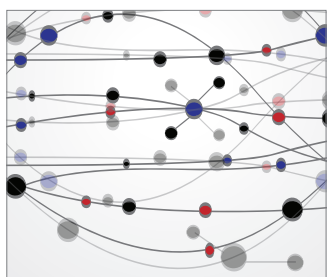

The Scientific World Journal
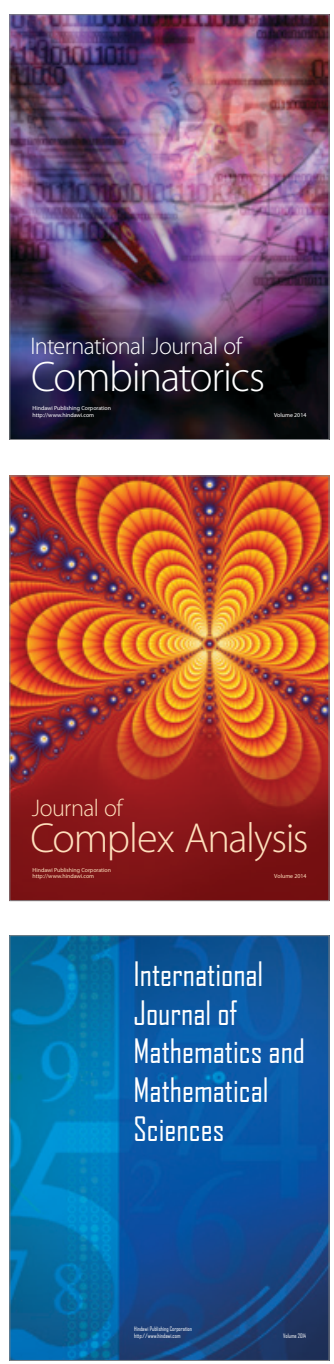
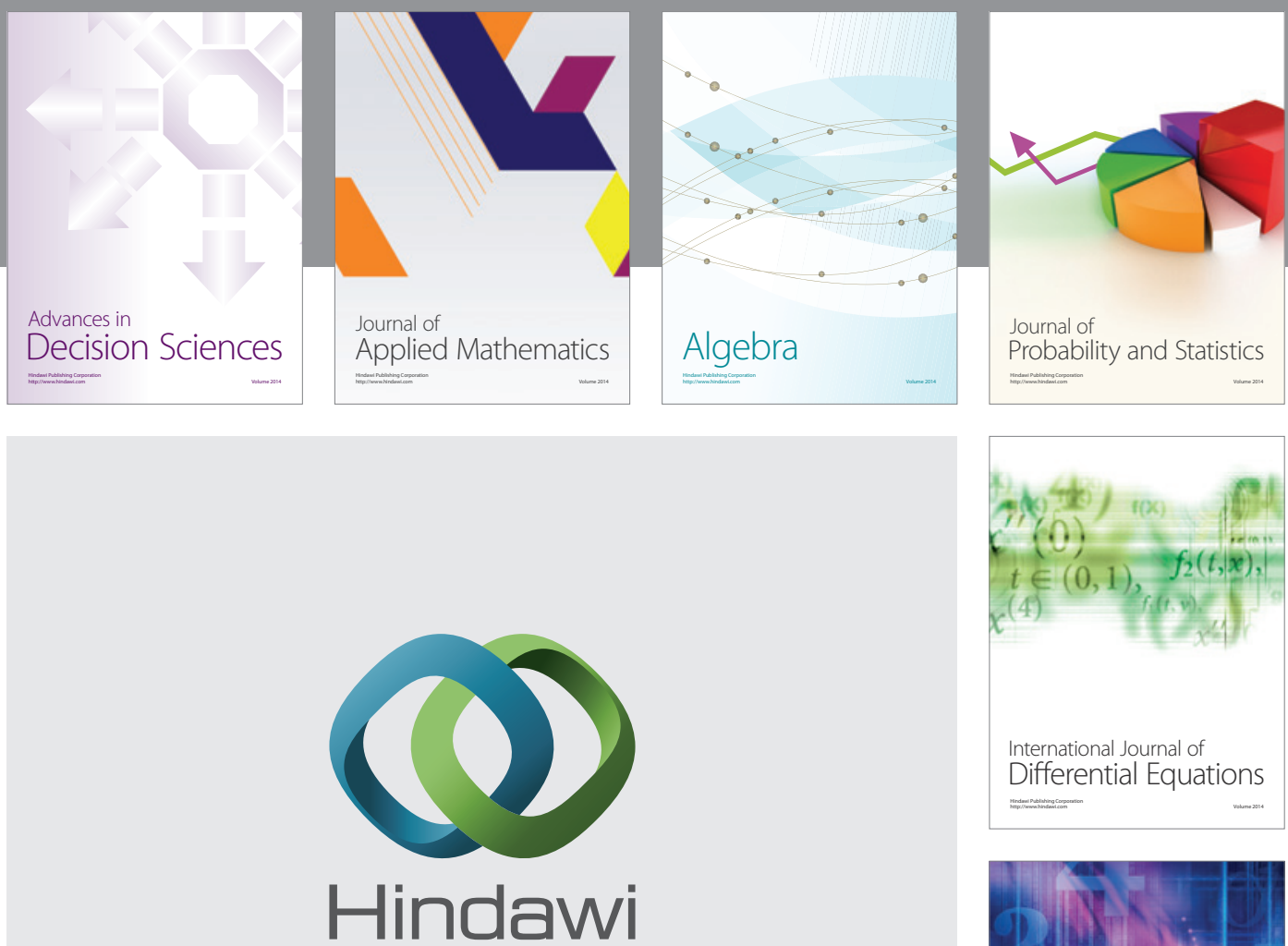

Submit your manuscripts at http://www.hindawi.com
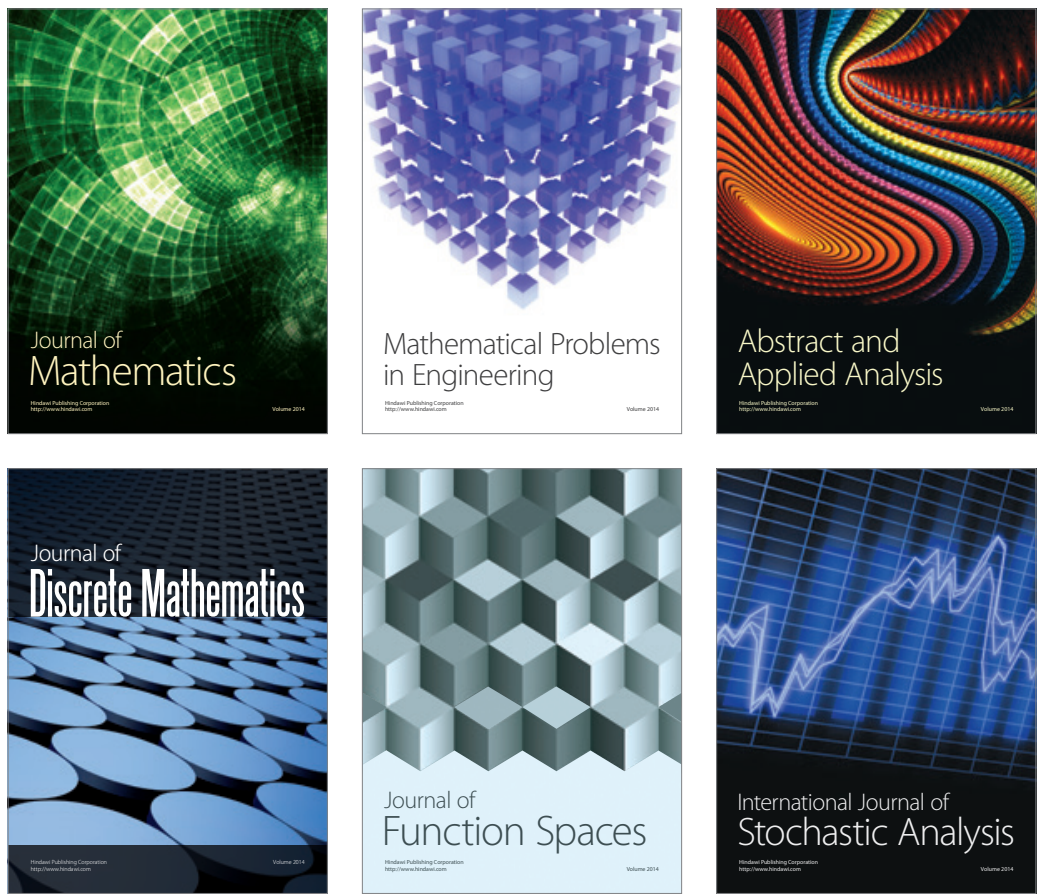

Journal of

Function Spaces

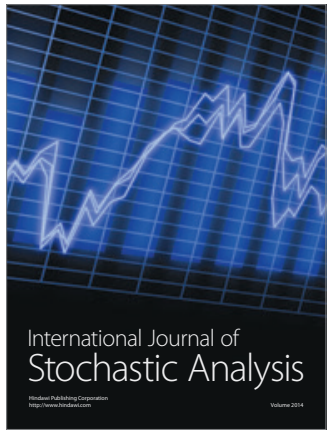

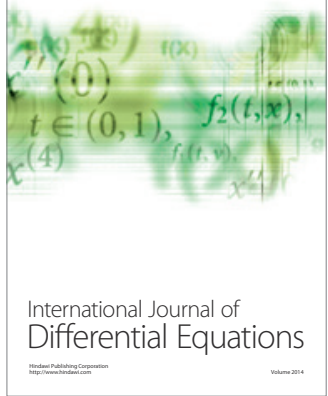
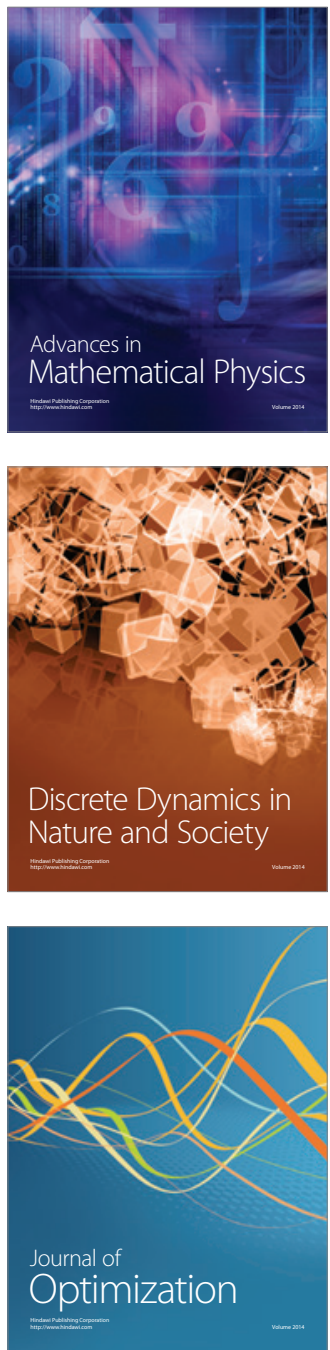